\title{
Geomagnetic storm effects on GPS based navigation
}

\author{
P. V. S. Rama Rao ${ }^{1}$, S. Gopi Krishna ${ }^{2}$, J. Vara Prasad ${ }^{1,}$, S. N. V. S. Prasad ${ }^{3}$, D. S. V. V. D. Prasad ${ }^{1} \operatorname{and~K.~Niranjan~}^{1}$ \\ ${ }^{1}$ Space Physics Laboratories, Department of Physics, Andhra University, Visakhapatnam, India \\ ${ }^{2}$ Institute of Scientific Research, Boston College, Boston, MA, USA \\ ${ }^{3}$ Chaithanya College of Engineering, Kommadi, Visakhapatnam, India \\ *on deputation from: Airports Authority of India (AAI), India
}

Received: 30 December 2008 - Revised: 9 April 2009 - Accepted: 14 April 2009 - Published: 7 May 2009

\begin{abstract}
The energetic events on the sun, solar wind and subsequent effects on the Earth's geomagnetic field and upper atmosphere (ionosphere) comprise space weather. Modern navigation systems that use radio-wave signals, reflecting from or propagating through the ionosphere as a means of determining range or distance, are vulnerable to a variety of effects that can degrade the performance of the navigational systems. In particular, the Global Positioning System (GPS) that uses a constellation of earth orbiting satellites are affected due to the space weather phenomena.

Studies made during two successive geomagnetic storms that occurred during the period from 8 to 12 November 2004, have clearly revealed the adverse affects on the GPS range delay as inferred from the Total Electron Content (TEC) measurements made from a chain of seven dual frequency GPS receivers installed in the Indian sector. Significant increases in TEC at the Equatorial Ionization anomaly crest region are observed, resulting in increased range delay during the periods of the storm activity. Further, the storm time rapid changes occurring in TEC resulted in a number of phase slips in the GPS signal compared to those on quiet days. These phase slips often result in the loss of lock of the GPS receivers, similar to those that occur during strong $(>10 \mathrm{~dB}) \mathrm{L}-$ band scintillation events, adversely affecting the GPS based navigation.
\end{abstract}

Keywords. Interplanetary physics (Interplanetary magnetic fields) - Ionosphere (Equatorial ionosphere; Ionospheric disturbances)

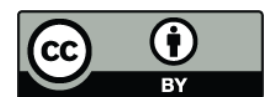

Correspondence to: P. V. S. Rama Rao (palurivsrao@gmail.com)

\section{Introduction}

The solar disturbances affecting the Earth's magnetic field, cause geomagnetic storms. Geomagnetic storms occur in conjunction with ionospheric storms. A geomagnetic storm usually consists of a small increase in the Earth's magnetic field, called initial phase, followed by a large decrease, called the main phase, which lasts for a day or two and then starts the recovery phase which normally takes a little longer than the main phase. During a geomagnetic storm, the Earth's magnetic field may change by about 100 to $300 \mathrm{nT}$ in a total of about $30000 \mathrm{nT}$ of the Earth. The geomagnetic storm caused by a solar flare usually starts off with a sudden increase of the Earth's magnetic field at the initial phase, and is called a sudden commencement (SC) storm. A storm caused by High Speed Solar Wind Stream (HSSWS), starts off gradually as HSSWS overtakes the Earth and this is described as gradual commencement storm (GC).

Modern navigational systems that use radio-wave signals reflecting from or propagating through the ionosphere as a means of determining range, or distance, are vulnerable to a variety of effects that can degrade the performance. In particular, the Global Positioning System (GPS), that uses a constellation of earth-orbiting satellites, are affected by space weather phenomena. Thus, the GPS receiver uses radio signals from known positions of several orbiting satellites (contained in the ephemeris) to determine the range from each satellite, and from these ranges (pseudo-ranges) the actual position of the receiver is determined. The radio signals used in this process must pass through the ionosphere, which introduces a propagation delay that depends on the ionospheric (TEC) and on the satellite elevation angle above the horizon.

Changes in the electron density, due to space weather activity, can change the speed at which the radio waves travel, introducing a propagation delay in the GPS signal. These delays can vary with time, and such intervals of rapid change can last for several hours, especially in the polar and auroral

Published by Copernicus Publications on behalf of the European Geosciences Union. 


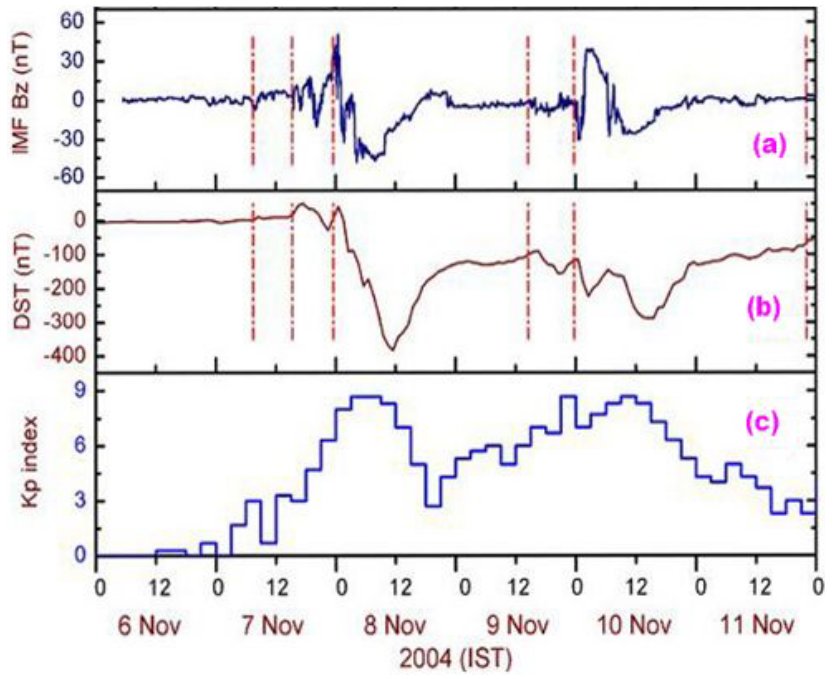

Fig. 1. The parameters (a) IMF $B_{z}$ component of solar wind (from ACE data); (b) the $D_{s t}$ index of geomagnetic activity (the vertical red (dotted) lines represent the storm sudden commencements generated by interplanetary shocks); and (c) the $K_{p}$ index.

regions, causing errors in the determination of the range. The rapid changes in electron density resulting from space weather disturbances may cause cycle slip in carrier phase tracking. Very rapid variations (less than about $15 \mathrm{~s}$ ) in the signal's strength and phase are known as "ionospheric scintillations". Scintillations can be particularly troublesome for receivers that are making carrier-phase measurements and may result in inaccurate or no position information; codeonly receivers are less susceptible to these effects.

The single frequency GPS receiver applications rely on the Klobuchar model (Klobuchar, 1987) to correct the measurements for the ionospheric error. The Klobuchar model, the official correction model broadcast by GPS satellites, predicts the vertical TEC at a given time and location in order to correct the measurements for the ionospheric effect. When space weather disturbances are active, the predicted TEC can deviate largely from the true value of the TEC. When large discrepancies appear, the accuracy of the application can be strongly degraded. As reported earlier by Rama Rao et al. (2006), the GPS receiver loss of lock occurs whenever the L-band scintillation index exceeds $0.5(10 \mathrm{~dB}$ power level) accompanied by the presence of bubbles/depletions in TEC. In this paper, we report that the loss of lock of GPS receiver signal may also occur whenever there is a fast rate of change in the TEC fluctuations, particularly during the periods of geomagnetic storm activity.

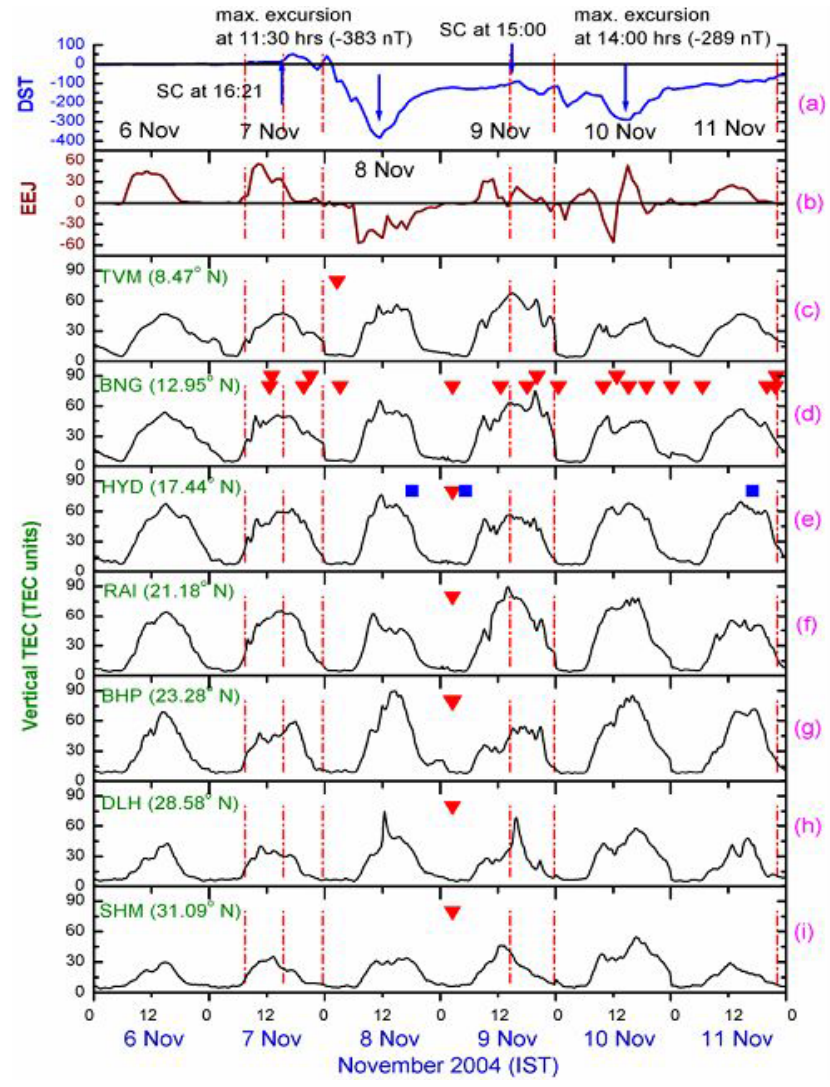

Fig. 2. Variation of TEC from a set of identified stations along the meridian of $77^{\circ} \mathrm{E}$ from the Indian sector, also the variation of equatorial electrojet strength along with $D_{s t}$ index is given for the storm period of November 2004. The Red and Blue symbols indicate phase slips of the GPS receiver resulting in loss of lock, the accompanying phase index $(\sigma)$ and $\mathrm{S} 4$ index, respectively.

\section{Solar geophysical effects associated with the geomag- netic storms of 8 and 10 November 2004}

A year after the extreme events that took place on the surface of the sun during the Halloween Storms (October-November 2003 storms), two similar successive storms were observed in November 2004. The geomagnetic storm occurred on 10 November 2004 ranks 3rd biggest storm in the current solar cycle, 23, and its maximum $A_{p}$ value was 206. Another strong geomagnetic storm has also occurred on 8 November 2004 with $A_{p}$ index of 169 making it the 8th largest storm in this cycle. However, the maximum $D_{s t}$ value on 8 November 2004 was $-383 \mathrm{nT}$, considerably stronger than $-296 \mathrm{nT}$ measured on 10 November 2004. These two storms have produced adverse affects in the communication and navigation systems such as GPS by introducing huge electron density gradients and scintillations.

The geomagnetic storm, with maximum $D_{s t}$ excursion of $-383 \mathrm{nT}$, occurred at 11:30 IST on 8 November 2004 (Fig. 1) and was preceded by three pulses of sudden commencements 
(SC) registered at 08:27, 16:21, and 23:57 IST on 7 November 2004, respectively. This indicates that the corresponding interplanetary disturbance was complicated and the preceding eruptive events that occurred on the Sun (source: Heliogram images of SOHO) during 4 and 5 November 2004 possibly contributed to this geomagnetic storm. The SC, of the geomagnetic storm which occurred on 9 November 2004 and started at 15:00 IST, is probably related to this event. The maximum excursion of this geomagnetic storm is $-296 \mathrm{nT}$ and occurred at 14:00 IST on 10 November 2004.

\section{Storm time variation of total electron content in the Indian sector}

In Fig. 2 the variation of the total electron content (TEC) from 6 to 11 November 2004 is presented, measured at seven different stations in the Indian sector (Figs. 2c to i) which are set along a common meridian of $77^{\circ} \mathrm{E}$ and covering the equatorial to the anomaly crest regions and beyond. This TEC data is derived from the dual frequency GPS receiver measurements made under the Indian ISRO-GAGAN programme. The $D_{s t}$ and the equatorial electrojet (EEJ) for the corresponding period are also presented in frames (a) and (b) of Fig. 2. It may be seen from this figure that the TEC is minimum (Fig. 2c) at the equatorial station, Trivandrum $\left(8.47^{\circ} \mathrm{N}\right.$ Geographic latitude) and increases gradually to the anomaly crest stations, Raipur $\left(21.18^{\circ} \mathrm{N}\right)$ and Bhopal $\left(23.28^{\circ} \mathrm{N}\right.$ ) (Fig. $2 \mathrm{f}$ and g) and decreases significantly (beyond the crest i.e., at Shimla $\left(31.09^{\circ} \mathrm{N}\right)$, Fig. $\left.2 \mathrm{i}\right)$ as expected. It may also be seen from Fig. $2 b$ that EEJ is significantly disturbed during the storm periods, the effects of which are clearly reflected both in the F-region altitudes and in the total electron content. But at the equatorial station Trivandrum (Fig. 2c), there is a significant increase in TEC during the recovery phase of storm-I, i.e., 9 November, while there is a significant decrease in TEC during the storm-II, i.e., 10 November where there is a counter electrojet associated with the storm. Whereas at the anomaly crest regions Raipur and Bhopal, a significant increase in TEC is seen during the maximum excursion times of $D_{s t}$ of both storms I and II (i.e., on 8 and 10 November 2004) and decreases in TEC during the recovery phases of both the storms. Thus, it suggests that the redistribution of ionization associated with the storminduced effects differs from the equator to the anomaly crest regions owing to the dynamical changes of the ionosphere over the low latitude regions. Further, it may be noticed from Fig. 2, followed by the sudden commencement of these storms (indicated by red dotted lines), that there are significant short-term fluctuations in the diurnal variation of the TEC plots, suggesting that the shocks might have induced wave-like perturbations in TEC. These perturbations, with time scales of about an hour that occur almost simultaneously at all the latitudes, could be due to the prompt penetration of high-latitude electric fields to lower latitudes (Tsurutani et al., 2004; Chi et al., 2005; Mannucci et al., 2005).

Furthermore, the occurrence of the SSC and the southward turning of IMF $B_{z}$ were observed during the local nighttime hours of 7 November 2004 (Fig. 1). The prompt penetration electric field of magnetospheric origin, characterized by southward turning of IMF $B_{z}$, produces a dawn-dusk electric field which is eastward during the daysides and westward in the nightsides in the equatorial ionosphere (Fejer et al., 1979; Sastri et al., 1992). These prompt penetration fields produce remarkable effects in the equatorial ionosphere as the $\boldsymbol{E} \times \boldsymbol{B}$ plasma drift is severely affected. Thus, such electric fields will make the equatorial F-region plasma drift upwards in the daytime and downwards in the nighttime. The normal zonal field in the equatorial F-region is eastward during the daytime and is westward during the nighttime. The penetration electric fields associated with the southward turning of the IMF $B_{z}$ are, therefore, so directed as to enhance the effective electric fields and the associated drifts at the equator. Fejer et al. (1979) also emphasized that prompt penetration electric fields reach the equatorial region only when IMF $B_{z}$ is stable and southward. In the present case, the IMF $B_{z}$ variations during the daytime hours of 8 November are also southward and stable and, hence, prompt penetration fields might have reached the equator. Zhao et al. (2005) recently reported that enhancement of the equatorial anomaly during the super storms of October-November 2003 is correlated with southward turning of the interplanetary magnetic field IMF $B_{z}$.

In Fig. 3, the contour diagrams of the variation of TEC at the seven locations along the common meridian of $77^{\circ} \mathrm{E}$ is presented before and during the storm period, i.e., from 6th to 11 November 2004, to examine the nature of the variation of the equatorial ionization anomaly (EIA). It may be seen from this figure that the anomaly formation on the quiet day i.e. 6 November, is fairly smooth and uniform over the latitudes from $15^{\circ}$ to $23^{\circ} \mathrm{N}$. Whereas on 7 November 2004, where the sudden commencements of storm-I started, there is a slight deviation in the formation of the crest of anomaly and is confined to 18 to $21^{\circ} \mathrm{N}$. And on the storm days of $8,9,10$ and 11 November 2004, which are highly disturbed days, the formation of the EIA is disturbed showing the formation of more than one contour of anomaly crest, clearly indicating the effects associated with the disturbed conditions during the storm periods. Further, it may also be seen on 8,9 and 10 November 2004, the anomaly crest attains a maximum value of 75 TEC units and its formation on the day of stormI moves to higher latitudes, i.e., $22^{\circ}$ to $24^{\circ} \mathrm{N}$. Thus, it may be inferred that the storm-induced changes (both increases and decreases) in TEC are significant in the equatorial and lowlatitude sectors and depend on the strength and phase of the storm and the direction of the IMF $B_{z}$. 


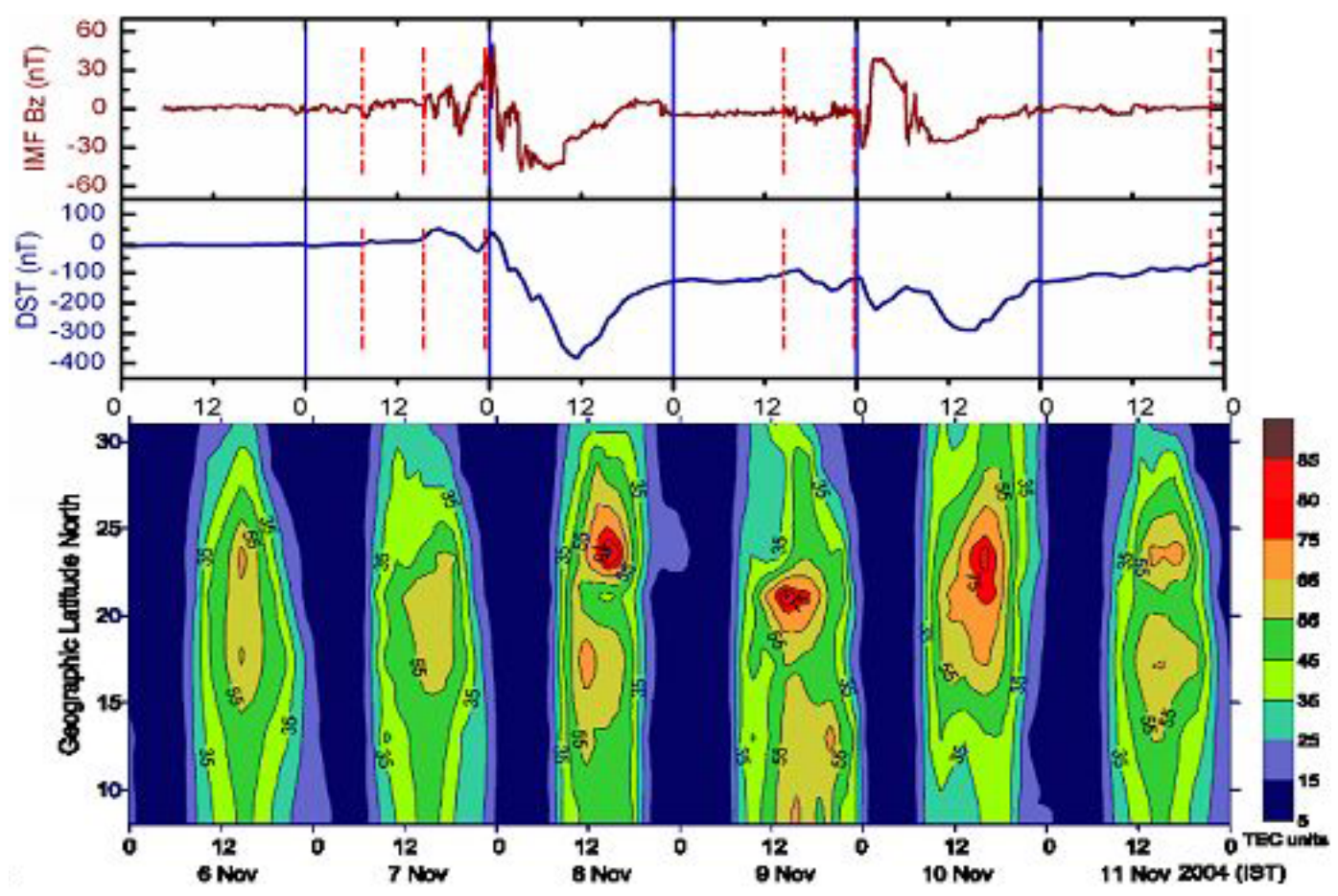

Fig. 3. TEC contour maps showing the formation of EIA crests, drawn as a function of latitude and time for the period from 6 to 11 November 2004 along with IMF $B_{z}$ and $D_{s t}$ index.

\section{Signal phase slips and loss of locks observed in GPS receivers during the geomagnetic storms of 8 and 10 November 2004}

As reported earlier by Rama Rao et al. (2006), the occurrence of amplitude scintillations greater than $10 \mathrm{~dB}\left(\mathrm{~S}_{4}\right.$ index $\approx 0.45$ ) at the L-band frequency of $1.575 \mathrm{GHz}$, results in the loss of lock of the GPS receivers, causing severe degradation in the performance of the GPS navigation systems. These scintillation effects are mostly confined to the nighttime sectors with greater probability of occurrence during the post sunset to midnight hours. It is also known, from several experimental results (Aarons, 1991; Abdu et al., 1995, and the references therein), that the geomagnetic storm activity, in general, inhibits the occurrence of ESF/Scintillations during most of the magnetic storm periods. However, from the recent studies (Basu et al., 2001a, b; 2005; Tulasiram et al., 2008), it is established that, in the longitude sectors where the main phase of the magnetic storm occurs during the local sunset hours, there is a greater probability of the storm induced electric fields to contribute to the increase in the eastward electric fields enhancing the post sunset vertical drifts at the equator, resulting in conditions conducive for the onset of ESF/scintillations. In the present study, an attempt is made to see if there are any noticeable effects induced in the GPS signals due to the magnetic storms of 8 and 10 November 2004.

Ann. Geophys., 27, 2101-2110, 2009
At equatorial and polar latitudes, the deep and rapid variations in TEC are caused by strong scattering of satellite signals from intense small-scale irregularities of the ionospheric F2-layer (Aarons, 1982; Yeh and Liu, 1982; Basu et al., 1988; Klobuchar, 1997; Pi et al., 1997; Aarons and Lin, 1999). This scattering results in deep amplitude fading of the trans-ionospheric signal leading to a phase slip at the GPS Lband frequencies (Skone and Jong, 2000). The slips of L1L2 phase measurements are most likely to be caused by the high level of slips of L2 phase measurements at the auxiliary frequency. The lower signal/noise ratio at $\mathrm{L} 2$ is primarily due to the fact that the L2 power at the GPS satellite transmitter output is $6 \mathrm{~dB}$ magnitude smaller compared to that at the frequency L1 using C/A code (Langley, 1998). However, the reason for the slips themselves can include several factors: the influence of additive interferences in the case of a low signal/noise ratio, the signal scattering from electron density irregularities, and the inadequate response of GPS receivers of some types to fast changes in daytime TEC at the auxiliary frequency, L2. The strong phase scintillations cause a frequency shift in the received signal resulting in loss of lock of the receiver.

The receiver's loss-of-lock indicator, which is sampled (recorded) as lock-time in seconds, is used to determine the break in satellite signal tracking. The receiver takes some re-initialization or re-acquisition time (several seconds to a few minutes) following the loss-of-lock, which is required to restart the integer-cycle phase ambiguity resolution process 


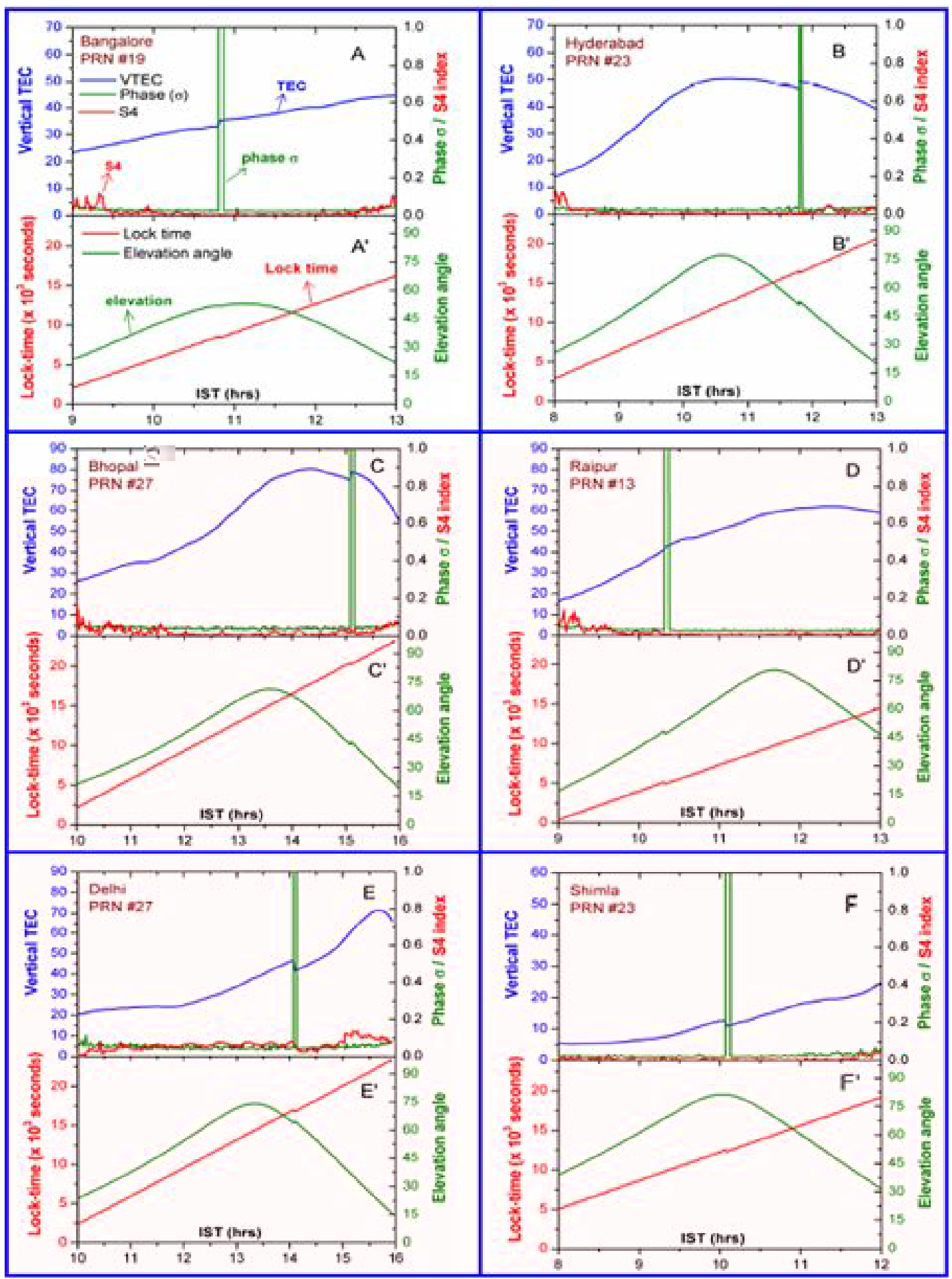

Fig. 4. Phase slips $(\sigma)$ observed in the GPS receivers during a quiet day, 6 November 2004, presented along with the corresponding S4 index, TEC and lock time on different satellite passes at the six different locations situated along the common meridian $77^{\circ} \mathrm{E}$ longitude.

or for the detrending highpass-filter to re-initialise lock of the carrier phase signal. Hence, in the SBAS systems if the receiver loses lock or does not maintain lock time long enough (i.e. $>240$ s) then the TEC data is discarded. A decrease in the number of GPS signals locked by a user receiver can re- sult in poor navigation accuracy. And, moreover, loss of signal lock at SBAS monitoring stations can degrade the broadcast correction information.

In the present analysis, the input data are the values of TEC determined from the phase difference of frequencies L1 and 


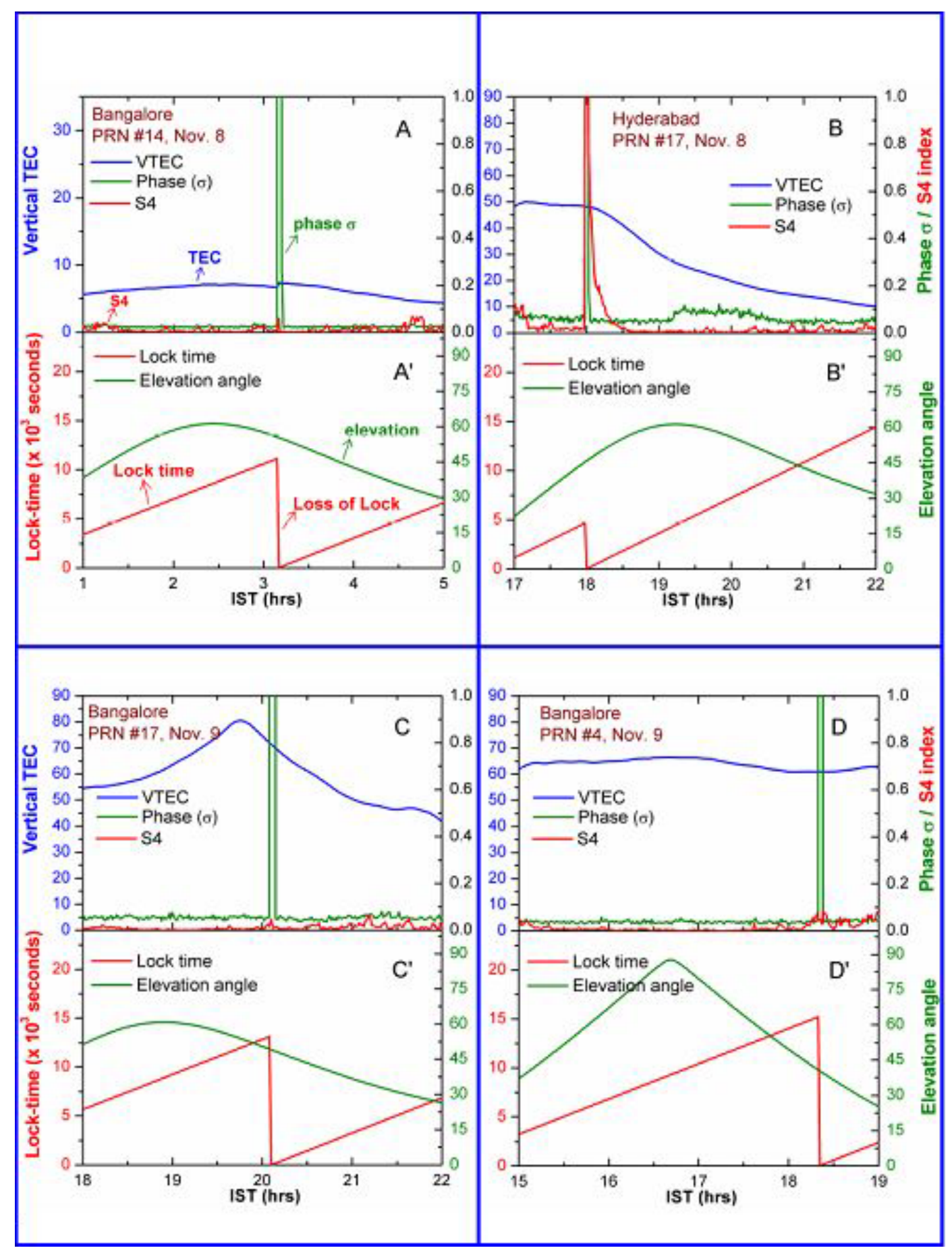

Fig. 5. Phase slips resulting in loss of locks during the geomagnetic storm period of 8 and 9 November 2004, presented along with the corresponding S4 index, TEC and lock time on different satellite passes at different locations.

L2 at the GPS receiver, and hence the phase slips that affect the TEC measurement are seen as sudden jumps in TEC and are also associated with the high phase scintillation index. The difference of TEC for a time interval of $60 \mathrm{~s}$ (which is the sampling rate of the GPS data used in the present study), exceeds the specified threshold value of 5TECU/min (derived by statistical analysis) is detected as a phase slip. There can be numerous phase slips that are less than the selected threshold value of 5 TECU. Such slips that accompany TEC variations of only a few TECU $(<5)$, are caused due to effects of ionospheric irregularities. 

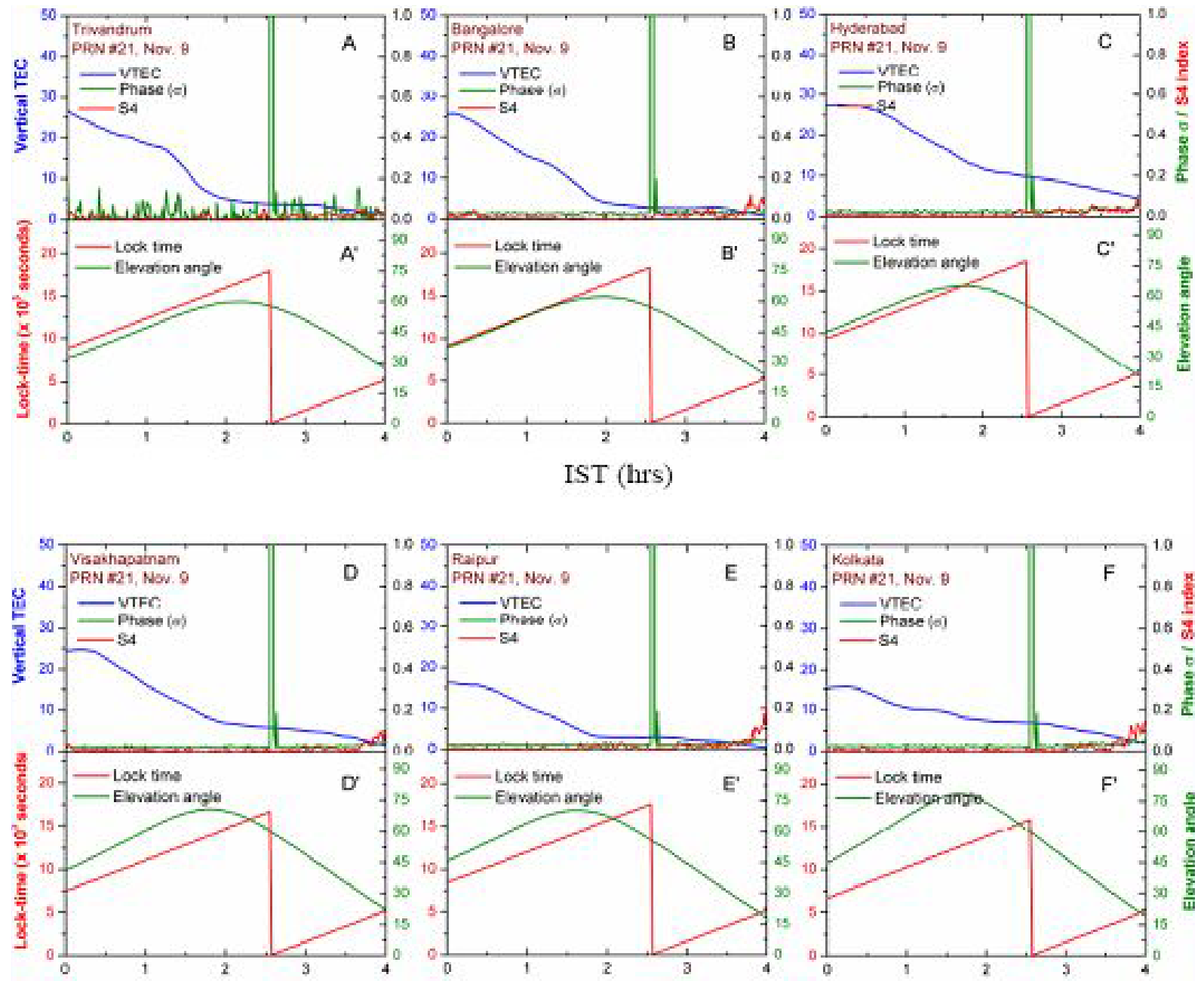

IST (hrs)

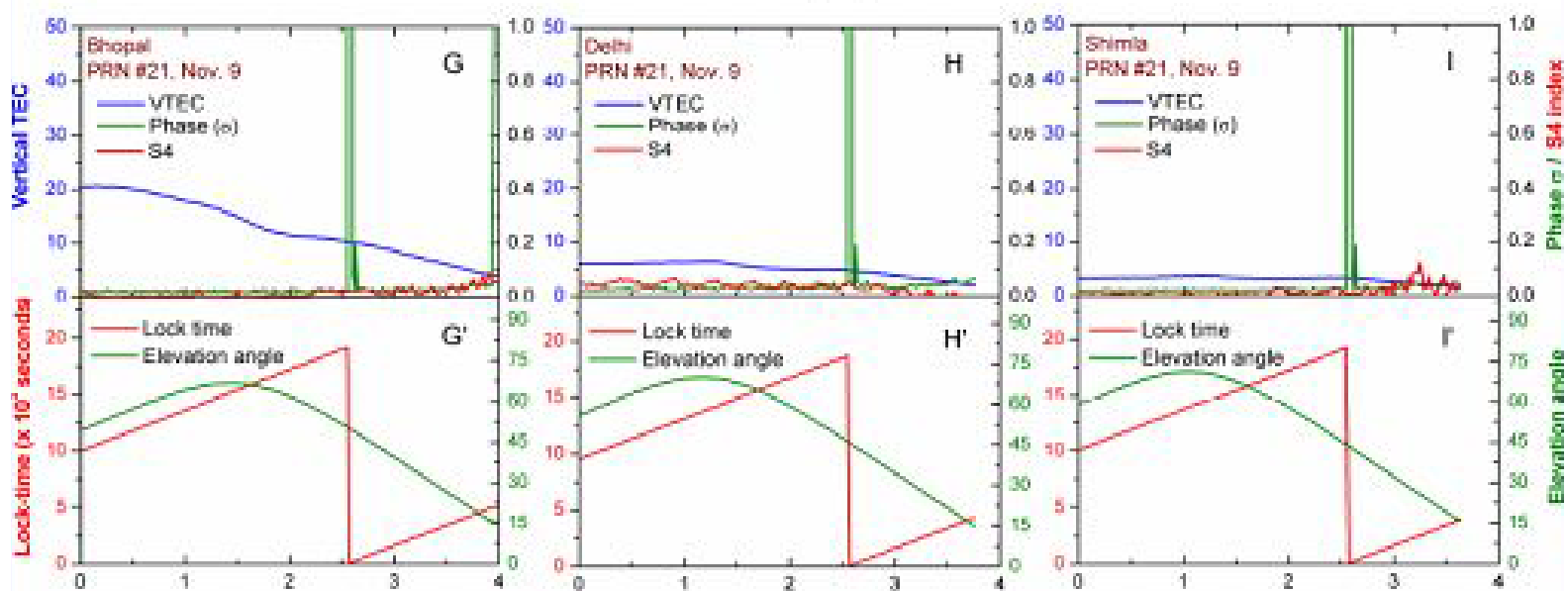

IST (hrs)

Fig. 6. Phase slips resulting in loss of locks during the storm period of 9 November 2004, presented along with the corresponding S4 index, TEC and lock time of satellite PRN 21 at different locations. 


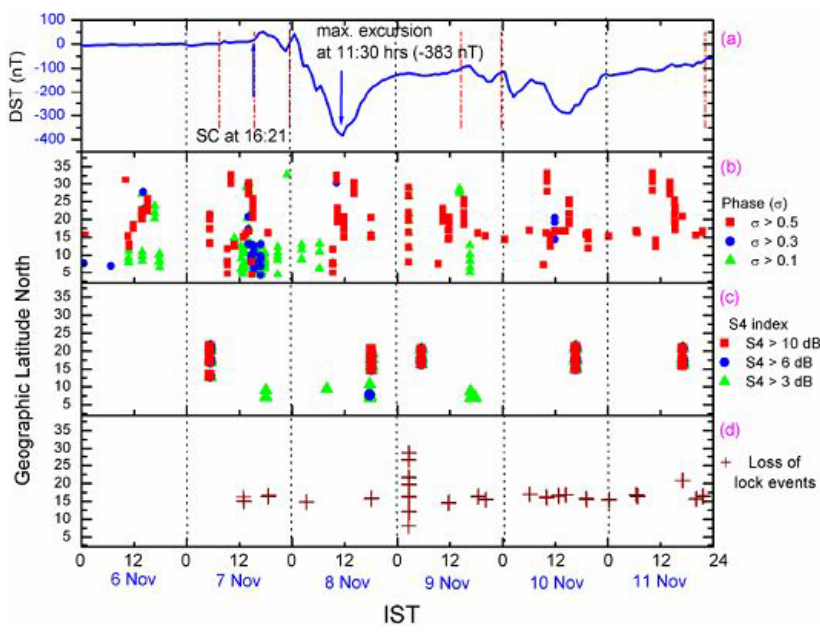

Fig. 7. Occurrence of phase slips as a function of latitude and local time (a) $D_{s t}$ variation during 6-11 November 2004 (b) associated with phase index $(\sigma),(\mathbf{c}) \mathrm{S} 4$ index, and (d) the resulting loss of lock events during the storm period, 6-11 November 2004.

Phase slips are also observed during the quiet days such as those shown in Fig. 4 for the typical day of 6 November 2004, which is a magnetically quiet day. In general, the phase slips and loss of locks observed during the quiet days are quite less in number compared to those observed during storm time period as may be seen from the storm time data of November 2004 presented in Figs. 5 and 6.

In Fig. 4, a series of plots of the vertical TEC is presented and the phase scintillation index $(\sigma)$ and $\mathrm{S}_{4}$ index $(A)$ as a function of local time along with their corresponding receiver lock times and elevation angles $\left(\mathrm{A}^{\prime}\right)$. In the series $\left(\mathrm{A}, \mathrm{A}^{\prime}, \mathrm{B}\right.$, $\mathrm{B}^{\prime}, \mathrm{C}, \mathrm{C}^{\prime}, \mathrm{D}, \mathrm{D}^{\prime}, \mathrm{E}, \mathrm{E}^{\prime}, \mathrm{F}, \mathrm{F}^{\prime}$ ) of pairs of plots representing the phases and TEC recorded from different satellite passes at different locations on a quiet day of 6 November 2004, it may be noticed that there are phase slips in TEC (indicated by blue lines, A to F), but no loss of lock events are observed on this day at any of the stations presented in the plots representing the lock time (red lines) presented in Fig. 4 ( $\mathrm{A}^{\prime}$ to $\mathrm{F}^{\prime}$ ). Whereas, when we look at similar plots presented in Figs. 5 and 6, they correspond to the storm days of 8 and 9 November 2004, where similar phase slips are observed but resulted in loss of locks of the GPS receivers as may be seen from the lock time (red lines) in the satellite passes from different locations presented in these figures. These figures clearly indicate that the storm time induced phase slips could be due to sudden ( $>5 \mathrm{TEC} / \mathrm{min}$ ) spatial or temporal changes in the electron density distribution compared to that of the quiet day which may result in loss of lock of the receivers.

In Fig. 7, where the phase $(\sigma)$ and amplitude (S4) indexes are presented along with the loss of lock events as a function of latitude and local time during the storm period, also shows the occurrences of phase slips for the entire period 6 to 11 November 2004, when the 8 and 10 November storms have occurred. Figure $7 \mathrm{~b}$ shows the phase slips and the associated phase scintillation $(\sigma)$ index of three different intensity levels $(>10 \mathrm{~dB},>6 \mathrm{~dB},>3 \mathrm{~dB})$ and Fig. $7 \mathrm{c}$ shows the phase slips that are accompanied with reduced signal-to-noise ratio as indicated by the amplitude scintillation (S4 index) at the three different power levels. Some of these phase slips, resulting in the loss of lock of the GPS receiver that are detected from the lock time of the receiver, are shown in Fig. 7d. It may also be seen from this figure that most of the slips are associated with phase $(\sigma)$ index rather than with $\mathrm{S} 4$ index. These loss of locks are caused as a result of rapid phase fluctuations in the received signal carrier exceeding the receiver's phaselock-loop (PLL) bandwidth, and in some cases resulting in the decrease of the signal-to-noise ratio beyond the threshold value of the receiver, which may also vary from receiver to receiver. However, from the communications and navigation point of view, these loss of lock events are undesirable and need to be accounted for in an appropriate manner.

It may also be observed from Fig. 5 that at Bangalore $\left(12.95^{\circ} \mathrm{N}\right.$ Geographic latitude, a near equatorial station) although the values of S4 index are very low $(\sim 0.1)$, loss of lock events are detected, perhaps due to rapid phase fluctuations present near the equator during the storm time (Afraimovich et al., 2002). Again, at Hyderabad $\left(17.44^{\circ} \mathrm{N}\right.$ Geographic latitude) on the storm day, 8 November at 18:00 IST, phase slips are also observed in all satellites tracks and resulted in loss of lock of the receiver simultaneously in six (PRNs 7, 9, 10, 17, 28 and 31) satellite passes out of eight passes recorded. In the remaining two passes (PRNs 4 and 24), there are phase slips but no loss of receiver locks detected. Further, on 9 November 2004, during the recovery phase of storm-I of 8 November 2004, phase slips resulting in loss of lock events are observed at all the 18 GPS stations in India during the satellite pass with PRN 21. Thus, it may be concluded that phase slips and loss of locks may also occur even during day times and on quiet days. But these phase slips and loss of locks increase significantly during storm times.

Phase slips of the GPS signal can be caused by the scattering from the geomagnetic field-aligned ionospheric E-layer small-scale irregularities (smaller than or of the order of the radius of the Fresnel zone), the amplitude of which increases with increasing geomagnetic disturbance level (Foster and Tetenbaum, 1991). Such a scattering can lead to strong signal fadings, and even to a particle screening of the GPS satellitereceiver propagation path. The increase in density of fatal slips during geomagnetic disturbances on the dayside can also be caused by limitations of the design and adjustment of the receivers used in the analysis, rather than the GPS signal scattering from ionospheric irregularities alone. An increase in slip density can be caused, in this case, by an inadequate response of GPS receivers of some types to fast changes in daytime TEC at the auxiliary frequency, L2. This effect prevents the identification of slips caused by phase fluctuations induced by the scattering from ion density irregularities (Afraimovich et al., 2002). 


\section{Summary of results}

It is known that during the space weather events, like geomagnetic storms and severe scintillation conditions, the equatorial ionosphere becomes highly disturbed and the space-based navigation becomes unreliable. Studies on the two overlapping geomagnetic storms, that occurred during 8 to 12 November 2004, have clearly revealed the adverse affects on the GPS range delay measurements as inferred from the TEC measurements made from a chain of dual frequency GPS receivers in the Indian sector. At the EIA crest regions during the storm time of 9 and 10 November 2004, the TEC values increased up to 90 TEC units as may be seen from Fig. 2 which corresponds to a range delay of about $15 \mathrm{~m}$. Furthermore, the EIA seen from the TEC measurements from a chain of seven Indian stations aligned on the common meridian of $77^{\circ} \mathrm{E}$, has shown a significant disturbed nature in the formation of the crest of the equatorial ionization anomaly.

The number of phase slips detected in GPS receivers during the storm time has increased significantly compared to those on quiet days. Some of these phase slips occurring during the storm time resulted in loss of locks of the GPS receivers owing to rapid phase fluctuations in the received signal due to rapid changes in TEC. These loss of lock events are found to be maximum at the near equatorial region, Bangalore (Figs. 2d and 7d). Furthermore, during the recovery phase of storm-I, at 02:34 IST of 9 November 2004, the phase slips are observed at all the 18 stations in India simultaneously, resulting in loss of lock of the receivers from the satellite signal of PRN 21. Thus, the phase slips may occur at all the stations in the equatorial and low-latitude ionospheric regions due to the sudden ionospheric electron density fluctuations during geomagnetic storm periods.

Acknowledgements. The authors wish to express their sincere thanks to the Indian Space Research Organisation (ISRO) and the Airports Authority of India (AAI) for providing the GPS TEC and scintillation data (GAGAN). The authors also wish to express their sincere thanks to the Indian Institute of Geomagnetism (IIG), Mumbai for providing the magnetometer data. Also one of the authors (S. Gopi Krishna) thanks the Council of Scientific and Industrial Research (CSIR) for providing him with a Senior Research Fellowship (SRF) to carry out this work.

Topical Editor M. Pinnock thanks C. Brunini and another anonymous referee for their help in evaluating this paper.

\section{References}

Aarons, J. and Lin, B.: Development of high latitude phase fluctuations during the January 10, April 10-11, and May 15, 1997 magnetic storms, J. Atmos. Terr. Phys., 61, 309-327, 1999.

Aarons, J.: The role of the ring current in the generation and inhibition of equatorial F-layer irregularities during magnetic storms, Radio Sci., 26, 1131-1149, 1991.

Aarons, J.: Global morphology of ionospheric scintillations, Proc. IEEE, 70(4), 360-378, 1982.
Abdu, M. A, Batista, I. S., walker, G. O., Sobral, J. H. A., Trivedi, N. B., and Depaula, E. R.: Equatorial ionospheric fields during magnetospheric disturbances; local time longitudinal dependences from recent EITS ciamaigns, J.Atmos. Solar-Terr. Phys., 57, 1065-1083, 1995.

Afraimovich, E. L., Lesyuta, O. S., Ushakov, I. I., and Voeykov, S. V.: Geomagnetic storms and the occurrence of phase slips in the reception of GPS signals, Ann. Geophys., 45(1), 55-71, 2002.

Basu, S., Basu, Su., Groves, K. M., MacKenzie, E., Keskinen, M. J., and Rich, F. J.: Near-simultaneous plasma structuring in the midlatitude and equatorial ionosphere during magnetic superstorms, Geophys. Res. Lett., 32, L12S05, doi:10.1029/2004GL021678, 2005.

Basu, S., Basu, Su., Groves, K. M., Yeh, H. C., Su, S.-Y., Rich, F. J., Sultan, P. J., and Keskinen, M. J.: Response of the equatorial ionosphere in the South Atlantic region to the great geomagnetic storm of July 15, 2000, Geophys. Res. Lett., 28, 3577-3580, 2001b.

Basu, Sa., Mackenzie, E., and Basu, Su.: Ionospheric constraints on VHF/HUF communications links during solar maximum and minimum periods, Radio Sci., 23, 363-378, 1988.

Chi, P. J., Russell, C. T., Foster, J. C., Moldwin, M. B., Engebretson, M. J., and Mann, I. R.: Density enhancement in plasmasphereionosphere plasma during the 2003 Halloween Super storm: Observations along the 330th magnetic meridian in North America, Geophys. Res. Lett., 32, L03S07, doi:10.1029/2004GL021722, 2005.

Fejer, B. G., Gonzalez, C. A., Farley, D. T., and Kelly, M. C.: Equatorial electric fields during magnetically disturbed conditions, 1, the effect of interplanetary magnetic field, J. Geophys. Res., 84, 5797-5802, 1979.

Foster, J. C. and Tetenbaum, D.: High resolution back scatter power observations of $440 \mathrm{MHz}$ E-region coherent echoes in MillstoneHill, J. Geophys. Res., 96, 1251-1261, 1991.

Klobuchar, J. A.: Ionospheric Time-Delay Algorithm for SingleFrequency GPS Users, IEEE Transactions on Aerospace and Electronic Systems, vol. AES-23(3), 325-331, 1987.

Klobuchar, J. A.: Real-time ionospheric science: the new reality, Radio Sci., 32, 1943-1952, 1997.

Langley, R. B.: GPS for Geodesy, Springer, Berlin, Heidelberg, New York, 111-149, 1998.

Mannucci, A. J., Tsurutani, B. T., Iijima, B. A., Komjathy, A., et al.: Dayside global ionospheric response to the major interplanetary events of October 29-30, 2003 "Halloween Storms", Geophys. Res. Lett., 32, L12S02, doi:10.1029/2004GL021467, 2005.

Pi, X., Mannucci, A. J., Lindgwister, U. J., and Ho, C. M.: Monitoring of global ionospheric irregularities using the worldwide GPS network, J. Geophys. Res. Lett., 24, 2283-2286, 1997.

Rama Rao, P. V. S., Gopi Krishna, S., Niranjan, K., and Prasad, D. S. V. V. D.: Study of spatial and temporal characteristics of Lband scintillations over the Indian low-latitude region and their possible effects on GPS navigation, Ann. Geophys., 24, 15671580, 2006, http://www.ann-geophys.net/24/1567/2006/.

Sastri, J. H., Ramesh, K. B., and Rangnath Rao, H. N.: Transient composite electric field disturbances near dip equator associated with auroral substorms, Geophys. Res. Lett., 19, 1451-1454, 1992.

Skone, S. and De Jong, M.: The impact of geomagnetic substorms on GPS receiver performance, Earth, Planets, Space, 52, 1067 
1071, 2000.

Tsurutani, B., Mannucci, A., Abdu, M. A., et al.: Global dayside ionospheric uplift and enhancement associated with interplanetary electric fields, J. Geophys. Res., 109, A08302, doi:10.1029/2003JA010342, 2004.

Tulasi Ram, S., Rama Rao, P. V. S., Prasad, D. S. V. V. D., Nirangan, K., Gopi Krishna, S., Sridharan, R., and Ravindran, S.: Local time dependent response of ost sunset ESF during geomagnetic storms, J. Geophys. Res., 113, A07310, doi:10.1029/2007JAo12922, 2008.
Yeh, K. C. and Liu, C. H.: Radio wave scintillations in the ionosphere, Proc. IEEE, 70(4), 324-360, 1982.

Zhao, B., Wan, W., and Liu, L.: Responses of equatorial anomaly to the October-November 2003 superstorms, Ann. Geophys., 23, 693-706, 2005, http://www.ann-geophys.net/23/693/2005/.

Zirker, J. B.: Coronal holes and high speed wind streams: a monograph from skylab solar workshop I, edited by: Zirker, J. B., Colorado Assoc. Univ. Press, Boulder, 1977. 